\title{
A Study on Ludwig Wittgenstein's Concept of Language Games and the Private Language Argument
}

\section{R. A. D. Priyanka Weerasekara}

Department of Languages, Sabaragamuwa University of Sri Lanka, Belihloya.

\begin{abstract}
The intent of this paper is to examine at what Wittgenstein's says about language as a use in the term of language games and the private language argument. The major argument of Wittgenstein on the language is the rules of the use of ordinary language is neither right nor wrong, neither true nor false, the language is merely useful for the particular applications in which they are applied .

On Wittgenstein's view, Language is defined not as a system of representation but as a system of devices for engaging in various sorts of social activity, hence 'the meaning of the word is its use in the language'. Wittgenstein gave us considerable help in understanding what he means by 'the meaning of the words is its use in the language' in the term of Language Games and the Private Language Argument.

There are various misunderstandings of Wittgenstein's philosophical ideas by professionals and ordinary readers. They have stemmed largely from a failure to grasp, or come to terms with this aspect of his thought. Thus the major objective of this study is to examine comprehensively what Wittgenstein says about the concept of Language game and the private language argument.

The study is based on empirical research methodology. Primary data will be collected by used empirical experiments. Secondary data will be collected by published documents.
\end{abstract}

\section{Intoduction}

Austrain British philosopher Ludwig Wittgenstein is generally considered to be one of the greatest philosophers in the $20^{\text {th }}$ century. He played a central role in the $20^{\text {th }}$ century analytic philosophical thought in topics as diverse as logic and language, perception and intention, ethic and religion, aesthetic and culture. By his own philosophical work and thought his influence on several generations of other thinkers, Wittgenstein transformed the nature of philosophical activity in the English speaking world.

The Wittgenstein family was large and wealthy. His home attracted people of culture, especially musicians and music remained important to Wittgenstein 
throughout his life. He was the youngest of eight children. As for his career, Wittgenstein studied mechanical engineering in Berlin and in 1908 went to Manchester, England to do research in aeronautics, experiments with kits. His interest in engineering led to an interest in mathematics which in turn got him thinking about philosophical questions about the foundation of mathematics. He visited the mathematician and philosopher Gottlob Frege (1848-1925), who recommended that he studied with Bertrand Russell (1872-1970) in Cambridge. At Cambridge Wittgenstein greatly impressed Russell and G.E Moor (1873- 1958), and began work on logic. When his father died in 1913 Wittgenstein inherited a fortune, which he quickly gave away. When war broke out the next year, he volunteered for the Austrian Army. He continued his philosophical work and won several, medals for bravery during the war. The result of his thinking on logic was the Tractatus Logico Philosophicus (1922 ) which was eventually published during his lifetime. Having thus, in his opinion, solved all the problems of philosophy, Wittgenstein became an elementary school, teacher in rural Austria, where his approach was strict and unpopular, but apparently effective. In 1929 he returned to Cambridge to teach at Trinity College, recognizing that in fact he had more work to do in philosophy. He became a professor of philosophy at Cambridge in 1939. After the war he returned to university teaching but resigned from his professorship in 1947 to concentrate on writing. Much of this he did in Ireland, preferring isolated rural places for his work. By 1949 he had written all the material that was published after his death as; Philosophical Investigations, arguably his most important work. He spent the last two years of his life in Vienna, Oxford and Cambridge and kept working until he died of prostate cancer in Cambridge in April 1951. His work from these last years has been published as; On Certainty. His last wards were, 'Tell them I've had a wonderful life' (Grayling, 2001).

There are two common recognized stages of Wittgenstein's thoughts; the early and the later, both of which are taken to be important in their respective periods. Wittgenstein tried to spell out precisely what a logically constructed language can and cannot be used to say. Its seven basic prepositions simply state that language, thought, and reality shares a common structure, fully expressible in logical terms.

The early Wittgenstein is epitomized in his Tractatus Logico- Philosophicus, 1922. By showing the application of modern logic and metaphysics, via language, he provides new insights into the relation between word, thought and language and thereby into the nature of philosophy. The later Wittgenstein is mostly recognized in his Philosophical Investigation, who took the more revolutionary step in criticizing all of traditional philosophy including its climax in his own early work in the field of philosophy. 
By the time Wittgenstein returned to Cambridge in 1928, however he had begun to question the truth of his earlier pronouncements. The problem with logical analysis is that it demands too much precision, both in the definition of words and in the representation of logical structure. In ordinary language, applications of a word often bear only a 'family resemblance' to each other, and a variety of grammatical forms may be used to express the same basic thought. But under these conditions, Wittgenstein now realized, the hope of developing an ideal formal language that accurately pictures the word is not only impossibly difficult but also wrongheaded.

During this fertile period, Wittgenstein published nothing, but worked through his new notions in classroom lecturers. Students who witnessed these presentations tried to convey both the style and the content in their shared notes, which were later published as; The Blue and Brown Books (1958). G.E. Moor also sat in on Wittgenstein's lecturer during the early thirties and later published a summary of his own copious notes. What appears in these partial records is the emergence of a new conception of philosophy (Nielsen \& Stehr, 2008).

\section{Wittgenstein's concept of Language Games}

Philosophers often create their own vocabularies by giving special meaning to ordinary terms and phrases. How does one know that a philosopher is using an ordinary term in the special sense? To make sense of these specially defined terms one must read with an eye that look for them. Sometimes this changes, but Wittgenstein gives us considerable help in understanding what he means by the term Language Game and the Private Language Argument.

Language Game is the key term in Wittgenstein's later philosophy. It is also a term that Wittgenstein teaches us as we begin to study his philosophy and it forms the foundation of much of his later work which challenges classical as well as many modern notions about language and philosophy. It is also a term that many ordinary readers misunderstand. They often presume that language game means 'word game', in the sense of people playing words tricks on each other. If we study Wittgenstein seriously, it is important that we do not make this mistake.

The key term of Wittgenstein later philosophy is 'Language Games' which the term that many ordinary readers misunderstand. What is the meaning of the 'word'? With this question, Wittgenstein opened one of the first works of his later philosophy, 'The Blue Book' in 1933. How do words have meaning?, What is the relationship between them and what are they about? Why does language have the structure? Such questions occupied throughout his philosophical career. In his early book 'The Tractatus Logico- Philosophis' he had answered them in one way, in later philosophy he rejected this answer 
and put forward a different one. But the changes were not merely between one answer and another to given question, it was a more radical change involving a different perception of the problem and of philosophical problems altogether. (Barrett, 1991).

The major argument of Wittgenstein's on the language is the rules of the use of ordinary language is neither right nor wrong, neither true nor false, the language is merely useful for the particular applications in which they are applied. The members of any community, college students, or rap musicians, for example; develop ways of speaking that serve their needs as a group, and these constitute the language game they employ. Human beings at large constitute a greater community within which similar, though more widely shared, language games get played. Although there is little to be said in general about language as a whole, therefore, it may often be fruitful to consider in detail the ways in which particular portions of the language are used. Even the fundamental truths of arithmetic, Wittgenstein now supposed, are nothing more than relatively stable ways of playing a particular language game. This account rejects both log cist and intuitionist views of mathematics in favour of a nominative conception of its use. $2+3=5$ is nothing other than a way we have collectively decided to speak and write a handy, shared language game. The point once more is merely to clarify the way we use ordinary language about members.

In the 1930s Wittgenstein became critical of his earlier picture theory of meaning. In his later work he uses a tool metaphor for language. The meaning of a word is no longer it's relation to some anomic fact; the meaning of a ward is in its use. We use language in a variety of way; to talk about science, religion, art and so on. The later Wittgenstein does not agree with the logical positivists that only scientific statements have meaning; science is only one way to talk about the world; only game. A language games reflect a human activity; a form of life. Words derived their meaning from the function they perform within the language games such as scientific language game, religious language game, an aesthetic language game and many others. A word may have a variety of usages. What these different usages have in common, Wittgenstein calls a 'Family resemblance'. Member of family bear a resemblance to each other, but no two members of family look exactly alike. The same is true for the use of words. The word games for example are used to talk about board games, card games, Olympic Games, ect. These games do not hold one essential quality in common; rather, they are overlapping and crises- crossing their similarity. In the opening section of the Investigations, Wittgenstein gave a simple statement of this view, describing it as a particular picture of the essence of human language.

'The individual ward of language name object- sentence is combinations of such names. In this picture of language we find the roots of following 
ideas; every ward has meaning. This meaning is correlated with the ward. It is the object for which the ward stands'(Wittgenstein, 1953).

It may be thought that there must be some such correlation between words and objects, language and reality, it would merely be some kind of game or ritual in which sounds are exchanged according to agreed patterns or rules. The quoted account of language would also explain why language is the way it is having the kind of structure and vocabulary that it has for these would be determined by the reality to which language corresponds.

The Tractatus tell us how language and the world must be, in the investigations by contrast we are told to 'look and see' how language actually used. Here we have the fundamental difference between the Tractatus way of doing philosophy and the approach of the later Wittgenstein which was to be purely descriptive. 'What cannot be said' this is the major theme of the Trctatus as a whole: since prepositions merely express facts about the world, prepositions in themselves are entirely devoid of value. The facts are just facts. Everything else, everything about which we care, everything that might render the world meaningful, must reside elsewhere. A properly logical language, Wittgenstein held, deals only with what is true. Aesthetic judgments about what is beautiful and ethical judgments about what is good cannot even be expressed within the logical language, since they transcend what can be pictured in thought. They are not facts. The achievements of the Tractatus itself are nothing more than useful nonsense: once appropriated, they are themselves to be discarded. The book concludes with the long statement: "whereof one cannot speak, thereof one must be silent'. This is a stark massage indeed, for it renders literally unspeakable so much of human life. As Wittgenstein's friend and colleague Frank Ramsy put it, 'What we can't say we can't say, and we can't whistle it either'.

Wittgenstein thought that philosophical problems arise when ' language goes on holiday' that is when we take a word and try to define the essence of beauty of knowledge, rather than seeing how these concepts are used in context, we will become confused.

Wittgenstein was aware that his earlier views were typical of perennial tendencies of human thought. What is the relation between the two works? How does he criticise his earlier view? He draws attention to the use of words in various practical situations, contrasting these with the abstract and uniform model of Tractatus.

Let us imagine a language is meant to serve for communication between a builder ' $A$ ' and assistance ' $B$ '. ' $A$ ' is building with building-stones; there are blocks, pillars, slabs and beams. ' $B$ ' has to pass the stones and that in the Oder in which 'A; need them. For this purpose they used a language consisting of the words 'block, pillar, slab, beams'. 'A' 
calls them out; ' $B$ 'brings the stone which he has learnt to bring at such and such ' $A$ ' call; conceive of this as a complete primitive language' (Wittgenstein, 1953).

In his investigation he draws attention especially to the practical aspects of language; describing words as tools and to the variety of words and sentences. To the question, 'How many kinds of sentences are there? He replies that there are countless. He introduces the term language games to be into prominence the fact that the speaking of language is part of an activity, or of a form of life and give a long list of examples of different language games such as reporting, speculating, singing, making a joke, translating, asking, cursing, greeting, paying. He then invites the reader to compare the multiple tools in language and of the ways they are used with what logicians have said about the structure of language.

Wittgenstein explained that the children brought up to perform these actions, to use these words as they do so, and to react in this way to the words of others. When the children first learn to speak a simple word like 'dog', the term does not necessarily fit into scheme of things in a comfortable way. We can imagine that it would be applied to a range of inappropriate things, not only cows and pigs, but it might be used to mean I want to go outside (where the children encountered dog), and this may happen more than we realize because we are so familiar with the concept 'dog' that we could presume that the children were using it within the rules of our language when the children are not. The point is that even though the exercises of pointing and naming may be useful in learning a language game, they are not enough to explain the acquisition of meaningful language. There is however another form of training children in language that will be helpful here. Philosophically, our culture tends to overlook this training, widespread though it is, in favour of training in pointing and naming. And children learning English are taught such mechanical responses before they understand the meaning of what they do and say. ' How old are you?' the adult says, and the children holds up three fingers without knowing that each finger stands for a year or even what a year is. According to Wittgenstein all these things are language games.

Wittgenstein says that people are trained 'react in this way 'to the words of others. In this language games, people seem to be using language to prompt people to do particular things such as brings beams of slabs. Think of others 'reactions' a similar language games might intend to prompt. However, that in all such simple situation, there is just the word and a single correct response.

'In the practise of the use of language one party calls out the word, the other act on them' (Wittgenstein: 1953).

Wittgenstein's view is that the term 'language games' has several related meanings. Sometimes it will refer to the primitive model of language that 
Wittgenstein constructs for us to study, sometimes to the supporting language practises that enable children to learn and finally it will refer to the whole of language like German or English as a language game.

Wittgenstein's position has however been misunderstood in a number of ways. Some commentators, disregarding his explicit rejection of 'theory' ascribed to him a theory of meaning; the meaning as 'use theory', the rule of use theory so on. No doubt the word 'theory' can be used in a broad sense, to include remarks of the kind made by Wittgenstein. It is however, liable to misleading in this context. For the sense in which there have been theories of meaning Wittgenstein's account is not a theory. In theories of this kind it is claimed that there is something other than words, which bestows meaning on them. In the Tractatus, this role is played by the corresponding 'object'. According to Tractatus the meaning of words, sentences are to be fixed by something outside language. But Wittgenstein's 'use' is not anything outside in the language; it is the meaningful use of words that he is talking about. Hence he is not explaining what meaning is, by reference to something other than meaning. It is not that he remarks as if we could say 'Here the word, there the meaning'. The meaning of the word and it use should rather be compared with the value of money and its use. The meaning of 'use' will be as multifarious, and as resistant to definition, as the various uses of language are. Similarly, it is a mistake to look for definitions, of his term 'language games' and 'form of life'. It is sometimes asked what exactly Wittgenstein meant by these, whether one is reducible to the other and so on. But the meaning of the term could be, like others, will depend on the use the marks of them in particular contexts. He states that he is going to use language games in a number of related ways.

When Wittgenstein speaks of use does he mean ordinary use? Wittgenstein is known as an 'Ordinary Language Philosopher', for he purposes to bring words back from their metaphysical to their everyday use. Now it may be objected that the words just mentioned 'language games', 'form of life' are themselves not examples of everyday use. But Wittgenstein is not committed to excluding non ordinary uses form the category of 'use'. However what he says about meaning and use will also apply to non ordinary uses. Thus, if a philosopher uses such words as 'knowledge', 'being', 'object' and so on, in particular ways, then his usage will show what he means by them. The purpose of bringing these words 'back to their everyday use' is to remind ourselves that they have, such a use, and to contrast this with the philosophers' use, avoiding the temptation to regard the later as giving the 'real' meaning.

Wittgenstein talks of language games primarily to teach us to dispel our language confusions, but this does not lead to a philosophy that tells us how to use language in our ordinary lives. Although Wittgenstein's earlier work was concerned with such a project, his later philosophy in which he introduces the term 'language games' is not. Wittgenstein says that our clear and simple 
language games are not preparatory studies for a future regulation of language as it was first approximations, ignoring friction and air resistance. The language games are rather set up as 'objects of comparison' which are meant to throw light on the facts of our language by ways not only of similarities, but also of differences. The idea is that if we think in terms of language games, if we ask how our language games are taught and how they are used, then we will begin to see past certain myths in our culture that trap us in a particular pictures. Getting past these pictures will enable us to see psychology with fresh eyes, but what we see is not predetermined. Wittgenstein does not tell us what we will see. He simply helps us see past these ancient pictures because a picture held us captive. And we could not get outside it, for it lay in our language and language seemed to repeat it to us inexorably. His propose is simply to help us see ahead of these muddles. He says that his aim is to teach us to pass from a piece of disguised nonsense to something that is patent nonsense.

Finally the term language game has several related meanings. Sometimes it will refer to the primitive models of language that Wittgenstein constructs for us to study. Sometimes to the supporting language practices that enable children to learn and finally, it will refer to the major languages like German or English as a language game.

On this concept of the philosophical enterprise, the vagueness of ordinary usage is not a problem to be eliminated but rather the source of linguistic riches. It is misleading even to attempt to fix the meaning of particular expressions by linking them referentially to things in the world. The meaning of a word or phrase or proposition is nothing other than the set of informal rules governing the use of the expression in actual life.

\section{The Private Language Argument}

The Private Language Argument of Philosophical investigations is closely related to the rejection of a solipsism which is based on an ego without a criterion of identity. The solipsist's ego lacks any criterion of personal identity and similarity, and similarity, if the quality of a sensory experience have completely disconnected from everything in a physical word, not only from any stimulus but also from any response. It would lack any criterion of type identity. The parallelism of the two critiques is very close in the lecturer notes in which Wittgenstein first developed the so called Private Language Argument (Mulhall, 2007).

The phrase Private Language in Wittgenstein questions refer to the speaker's immediate private sensations. But what is meant here by 'refer'? How do words refer to sensation? He invites us to consider how the connection between words and sensations is made in the course of learning to speak. How does a human being learn the meaning of the names of sensations? In the case of 
pain, he says, it can be done by connecting words with the natural, pre-verbal expressions of pain.

One application of the new analytic technique that Wittgenstein himself worked out appears in several connected sections of the Philosophical Investigations (1953). In discussions of the concept of 'understanding', traditional philosophers tended to suppose that the operation of the human mind involves the continuous operation of an inner or mental process of pure thinking. But Wittgenstein pointed out that if we did indeed have private inner experiences, it would be possible to represent them in a corresponding language. The words of the Private Language in Wittgenstein questions are to refer to the speaker's immediate private sensations. He invites us to consider how the connection between words and sensations is made in the course of learning to speak. Wittgenstein asked 'How do words refer to sensations? How the connection between the name and the thing is named setup? The view of language that he had introduced in the opening section of his book named Philosophical Investigations is as follows;

'Every word has a meaning. This meaning is correlated with the word. It is the object for which the word stands'

Wittgenstein's discussion proceeds at two levels. First he considered whether some of our actual language is private in the relevant sense. When the person speaks of his own sensations, for example pain, is not his meaning private, In this case it may seem that, correct usage is not dependent on a consensus, but on an individual's recognition of his own sensation. But Wittgenstein clams that the meaning of 'pain' is connected with certain behaviour, so that correct usage of this word not a private matter but subject to the check of others. He pointed out that I would never have learned the meaning of the word 'pain' without the aid of other people, none of whom have access to the supposed private sensations of pain that I feel. For the word 'pain' to have any meaning at all presupposes some sort external verification, a set of criteria for its correct application, and they must be accessible to others as well as to myself. Thus, the traditional way of speaking about pain needs to be abandoned altogether. (Hacker, 1986).

Notice that exactly the same kind of argument will work with respect to every other attempt to speak about our supposedly inner experiences. There is no systematic way to coordinate the use of words that express sensation of any kind with the actual sensations that are supposed to occur within myself and other agents. Wittgenstein proposed that we imagine that each human being carries a tiny box whose contents is observed only by its owner: even if we all agree to use the word 'beetle' to refer to what is in the box, there is no way to establish a non linguistic similarity between the contents of my own box and that of anyone else's. Just so, the use of language for the pains or other 
sensations can only be associated successfully with dispositions to behave in certain ways. Pain is whatever makes someone (including me) writhe and groan. (Kripke, 1982).

In his discussion of sensation in the Private Language Argument, Wittgenstein uses pain as his main example. He probably considered that the attraction of the 'Private object' view was especially powerful in this case.

Having reached his conclusion in Philosophical Investigation about 'Agreement in Judgements' he proposes the questions about whether there could not be a language in which a person describes his inner experiences such as feeling for his private use. He says;

'If there were something that is the meaning of the word pain when I say I am pain, then it would be seem, it could only be the pain itself. And in that case the meaning of the word would be personal to me and not communicable to others and the correct use of the sentence would depend on my recognition of what I feel and not my agreement with others.'(Wittgenstein, 1953).

If we take seriously the idea that the meanings are private, then the fact that people communicate with one another will call for explanation. And indeed, what we find in the work of these and another philosopher is the view that meaning is two folded. So that alongside the private meaning, there is also sheared meaning or shared use, as distinct from the meaning, which comes into play when people talk to each other.

Wittgenstein says that Language Games can be played only with living beings and it cannot be played in the case of inanimate objects such as a chair or a stone. The relevant resemblance to a living human being is a matter of degree. For instance dogs, can engage our feelings in a deeper and richer way than an insect, but the case of the dog still falls far short of that of a fully developed human being. According to Wittgenstein, it is the logical environment that is lacking.

'Why can't a dog stimulate pain? Is he too honest? Could one teach a dog to stimulate pain? perhaps it is possible to teach him to howl on particular occasions as if he was in pain, even which is necessary for his behaviour o be real stimulation is missing'(Wittgenstein: 1953).

\section{Conclusion}

On Wittgenstein's view, the world consists entirely of facts. Human beings are aware of the facts by virtue of our mental representations or thoughts, which are most fruitfully understood as picturing the way things, are. These thoughts are, in turn, expressed in prepositions whose form indicates the position of 
these facts within the nature of reality as a whole and whose content presents the true conditions under which they correspond to the reality. Everything that is true, all the facts that continue the world can in principle is expressed by atomic sentences. Imagine a comprehensive list of all the true sentences. They would picture all the facts there are, and this would be an adequate representation of the world as a whole.

Wittgenstein's view what philosophy is changed little over his life. In the Tractatus he says that Philosophy is not one of the natural sciences and philosophy aims at the logical clarification of thoughts. According to Tractatus, the tautologies show the logical form of language and the word. The argument of the Tractatus is based on the prepositions of logic and tautologies, and in which the definitive views of the Tractatus are demonstrated. It should be no surprise that the proper interpretation of the logical constants expressed in the fundamental idea, plays a key role in the proper interpretations of the prepositions of logic. This account of the nature of the logical prepositions is the true point of entry into the philosophical system of the Tractatus. The Tractatus is distinguished among works on analytical philosophy in its concern with the nature of philosophical truth. Wittgenstein's conception of philosophical truth is the foundation of the system of the Tractatus.

Wittgenstein's own evaluation of the truth of the Tractatus has been changed in his later writings. In the preface to the Philosophical Investigations for example, Wittgenstein refers to the 'grave mistakes' of the Tractatus. One issue which must be settled is the actual connection of Wittgenstein earlier and later philosophies, and it is responsible to expect that in the clearer resolution of this issue. Something about the truth must become clear as well. But Wittgenstein's later writings seem generally critical of the Tractatus. (Baker and Hacker, 1980).

Wittgenstein was not, of course, the first to claim to be making a new start in the way of thinking of philosophy. Such a claim was made by the logical positivists. But this is not true of Wittgenstein's descriptive philosophy, though misguided attempts have frequently been made to fit his ideas into one of the traditional kinds. I believe that this involves a failure to come to terms with essential originality of his later idea, and their discontinuity with what had gone before.

Wittgenstein himself said that his philosophy was no longer the same subject as the traditional one. It was 'one of the heirs of the subjects' which was used to be called 'philosophy' and this as an appropriate remark. Another source of misunderstanding has been the desire to ascribe to him hard and fast views or claims in place of what he actually says, which may be more tentative and qualified. A common pitfall here is to treat as obviously rhetorical some of his questions which were really intended as questions, and not to have 'obvious' answers supplied by the reader. 
Wittgenstein's new way of doing philosophy goes against the grain of tradition. But there is more to this than merely tradition. According to the Philosophical Investigation, philosophy was t be a struggle against the bewitchment of our understanding by means of language.

Wittgenstein was not a careless or obscure writer. He went to infinitive pains in drafting and redrafting his remarks until they would express exactly what he intended. Wittgenstein's message was not excessively complicated and he was right to describe his work as one of the things familiar to us. The difficulty lies in grasping the full importance of his massages and method, and in being prepared to open one's mind to the radical change of that this calls for.

This paper was written on Wittgenstein's concept of Language Games and Private Language Argument, in the course of writing. However, I found that one particular aspect of his thought seemed especially important. In the Philosophical Investigations Wittgenstein rebels against his former idea of language and came to think of language not as a system of representation but as a system of devices for engaging in various sorts of social activity, hence 'the meaning of the word is its use in the language'.

Throughout the paper I discussed Wittgenstein's philosophical thought in term of Language Games and the Private Language Argument which he had discussed in his later philosophy. For as will become clear, I share Wittgenstein's views, as I understand them, to a very large extent. My aim therefore, is not merely to present the view of a great thinker as clearly as possible, but to advocate and defend a philosophy of whose correctness and importance I am convinced of.

\section{References}

Baker, G.P \& Hacker, P.M.S (1980) Wittgenstein: Understanding and Meaning, Blackwell.

Barrett, Cyril (1991) Wittgenstein on Ethics and Religious Belief, Blackwell.

Grayling, A.C (2001) Wittgenstein: A Very Short Introduction, Oxford University Press.

Hacker, P.M.S (1986) Insight and Illusion: Themes in the Philosophy of Wittgenstein, Clarendon Press.

Kripke, Saul (1982) Wittgenstein on Rules and Private Language, Blackwell Publishing.

Mulhall, Stephen(2007) Wittgenstein's Private Language: Grammar,Nonsense, and Imagination in Philosophical Investigations, Blackwell Publishing. 
Nielsen \& Keld Stehr (2008) The Evolution of the Private Language Argument, Aldershot: UK: Ashgate Publishing Group.

Wittgenstein, Ludwig (1953) Philosophical Investigations, Blackwell Publishing. 